\title{
AUDIT STRUKTUR GEDUNG BANK $X$ KOTA BANJARMASIN
}

\section{Syapril Janizar ${ }^{1}$ Felix Setiawan ${ }^{2}$ Denah Harun Saputra ${ }^{3}$}

\author{
${ }^{1,2}$ Dosen Teknik Sipil Universitas Winaya Mukti; ${ }^{3}$ Alumni Teknik Sipil Universitas Winaya Mukti \\ Email : sjanizar@yahoo.com; felix.sehoey@gmail.com; denahharunsaputra@gmail.com
}

\begin{abstract}
This study aims to ensure that the existing conditions of the structure of the Bank X Building in Banjarmasin City are still able to withstand the burden that occurs and can meet the service period properly in accordance with applicable regulatory standards. In this study, structural inspection is described structural inspection, starting from visual inspection, undestructive inspection of building structures by testing the compressive strength of concrete using a Hammer Test, testing the number of reinforcement, reinforcement distance and a concrete blanket using the Rebar Locator / Cover Meter and verticality checking / building rigidity. In addition, the results of the examination of the structure of the building were analyzed by modeling the existing building structure elements using tools or structural analysis software. The final result of this study is to provide recommendations for structural improvement in accordance with the level of damage that occurs.
\end{abstract}

Keywords: Testing, Analysis and Recommendations.

\begin{abstract}
ABSTRAK
Kajian ini bertujuan agar kondisi eksisting struktur Gedung Bank X Kota Banjarmasin masih mampu menahan beban yang terjadi dan dapat memenuhi masa layannya dengan baik sesuai dengan standard peraturan yang berlaku. Dalam kajian ini pemeriksaan struktur diuraikan pemeriksaan struktur diuraikan mulai dari pemeriksaan secara visual, pemeriksaan struktur bangunan yang bersifat tidak merusak (undestructive) dengan melakukan pengujian kuat tekan beton menggunakan alat Hammer Test, pengujian jumlah tulangan, jarak tulangan dan selimut beton menggunakan alat Rebar Locator/ Cover Meter dan pemeriksaan verticality/ketegakan bangunan. Selain itu dari hasil pemeriksaan struktur bangunan tersebut dilakukan analisa dengan melakukan pemodelan elemen struktur bangunan eksisting yang menggunakan alat bantu atau Software analisa struktur. Hasil akhir dari kajian ini adalah memberikan rekomendasi perbaikan struktur sesuai dengan tingkat kerusakan yang terjadi.
\end{abstract}

Kata Kunci: Pengujian, Analisa dan Rekomendasi.

\section{PENDAHULUAN}

Sehubung dengan adanya beberapa perubahan fungsi ruangan dan perpanjangan masa layan bangunan maka diperlukan suatu audit struktur yang bertujuan untuk mengetahui tingkat kelaikan dan keandalan struktur Gedung Bank X Kota Banjarmasin berdasarkan standard aturan yang berlaku. 


\section{TINJAUAN PUSTAKA \\ Pemeriksaan Visual}

Pemeriksaan visual dapat dilakukan untuk mengetahui kerusakan yang terdapat pada bangunan. Kerusakan yang terdapat pada bangunan dikategorikan menjadi 5, yaitu: 1) Kerusakan Ringan Non-Struktur, 2) Kerusakan Ringan Struktur. 3) Kerusakan Struktur Tingkat Sedang, 4) Kerusakan Struktur Tingkat Berat, dan 5) Kerusakan Total. Kategori kerusakan non struktur ini meliputi; a) Retak halus (lebar celah lebih kecil dari $0.075 \mathrm{~cm}$ ) pada plesteran, b) Serpihan plesteran berjatuhan, c) Mencakup luas yang terbatas. Tindakan yang perlu dilakukan adalah perbaikan (repair) secara arsitektur tanpa mengosongkan bangunan. Kerusakan Ringan Struktur meliputi kerusakan, yaitu: 1) Retak kecil (lebar celah antara 0.075 hingga $0.6 \mathrm{~cm}$ ) pada dinding, 2) Plester berjatuhan, 3) Mencakup luas yang besar, 4) Kerusakan bagian-bagian nonstruktur seperti cerobong, lisplang, dll, 5) Kemampuan struktur untuk memikul beban tidak banyak berkurang, 6) Laik fungsi/huni Tindakan yang perlu dilakukan adalah perbaikan (repair) yang bersifat arsitektur agar daya tahan bangunan tetap terpelihara. Perbaikan dengan kerusakan ringan pada struktur dapat dilakukan tanpa mengosongkan bangunan. Kerusakan Struktur Tingkat Sedang meliputi kerusakan, yaitu: 1) Retak besar (lebar celah lebih besar dari 0,6 cm) pada dinding; 2) Retak menyebar luas di banyak tempat, seperti pada dinding pemikul beban, kolom; cerobong miring, 3) Kemampuan struktur untuk memikul beban sudah berkurang sebagian; 4) Laik fungsi/huni. Tindakan yang perlu dilakukan adalah, 1) restorasi bagian struktur dan perkuatan (strenghtening) untuk menahan beban gempa; 2) perbaikan (repair) secara arsitektur; 3) bangunan dikosongkan dan dapat dihuni kembali setelah proses restorasi selesai, 4) Kerusakan Struktur Tingkat Berat meliputi kerusakan, yaitu: 1) dinding pemikul beban terbelah dan runtuh; 2) bangunan terpisah akibat kegagalan unsur-unsur pengikat; 3) kira-kira 50\% elemen utama mengalami kerusakan; 4) tidak laik fungsi/huni. Tindakan yang dapat dilakukan dengan memerlukan untuk merubuhkan bangunan. Atau dilakukan restorasi dan perkuatan secara menyeluruh sebelum bangunan dihuni kembali. Dalam kondisi kerusakan seperti ini, bangunan menjadi sangat berbahaya sehingga harus dikosongkan. Kerusakan Total merupakan kerusakan yang mempunyai kategori, yaitu: 1) Bangunan roboh seluruhnya (> 65\%), 2) Sebagian besar komponen utama struktur rusak, 3) Tidak laik fungsi/ huni. Tindakan yang perlu dilakukan adalah merubuhkan bangunan, membersihkan lokasi, dan mendirikan bangunan baru.

\section{Pengujian Kuat Tekan Beton}

Pengujian yang dilakukan salah satunya adalah pengujian kuat tekan beton dengan menggunakan alat Hammer test, metode pelaksanaan pengujian ini mengacu pada SNI 03-4430-1997. Alat palu beton ini berbentuk silinder, dimana bagian tengahnya terdiri dari poros yang dilengkapi dengan cincin yang dapat ditembakkan dan membentur ujung poros dan menyalurkannya pada beton yang diperiksa dengan menekan tombol pelontar. Pada alat ini juga dilengkapi besaran angka tertentu yang kemudian dikonversikan terhadap perkiraan mutu beton. 


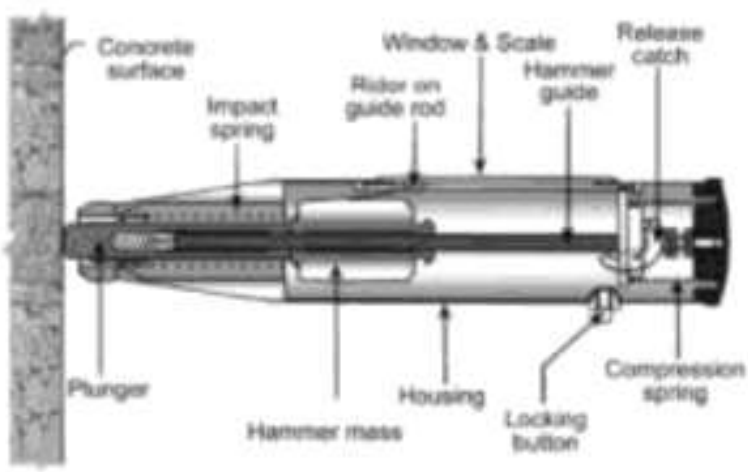

Gambar 2.1. Alat Hammer Test.

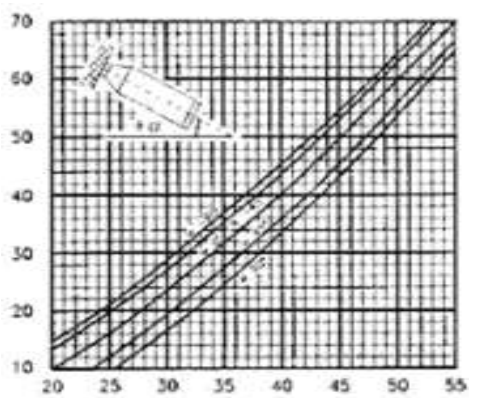

Gambar 2.2. Grafik hubungan nilai lenting palu beton dengan kuat tekan beton.

\section{Pengujian Rebar Locator/Cover Meter}

Pengujian Rebar Locator/Cover Meter untuk mengetahui dimensi, jarak dan jumlah tulangan serta selimut beton terpasang. Menggunakan alat Profometer Testing Apparatus dengan metode pengujian berdasarkan British Standart 1881: Part 204. Prinsip pengujian ini dengan menggunakan medan elektromagnetik yang dipancarkan melalui probe. Ketika tulangan baja atau benda metal lainnya berada di medan tersebut, garis gaya medan elektromagnetik akan terdistorsi. Baik orientasi dan kedekatan logam dengan probe akan mempengaruhi pembacaannya. Oleh karena itu memungkinan untuk menemukan lokasi tulangan baja dan orientasinya.

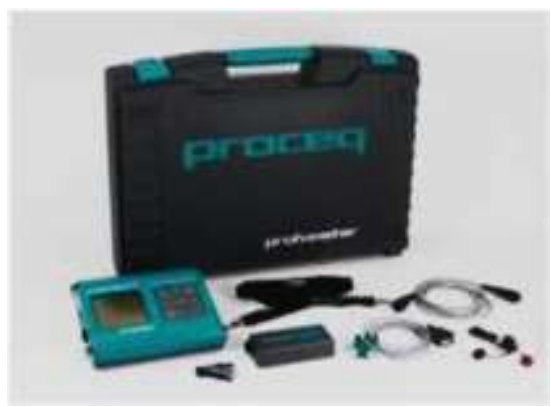

Gambar 2.3. Alat Uji R-Bar/Profometer 


\section{Pengujian Verticality}

Pemeriksaan Verticality/ Kemiringan Bangunan untuk mengetahui tingkat kemiringan yang terjadi pada bangunan terkait dengan besarnya simpangan antar lantai (story drift) bangunan pada bagian eksterior. Setelah diketahui kemiringan tersebut lalu diverifikasi dengan batas yang diijinkan mengacu pada SNI 1729 tahun 2012. Alat yang digunakan adalah dengan Theodolite dapat dilihat pada Gambar 2.3.

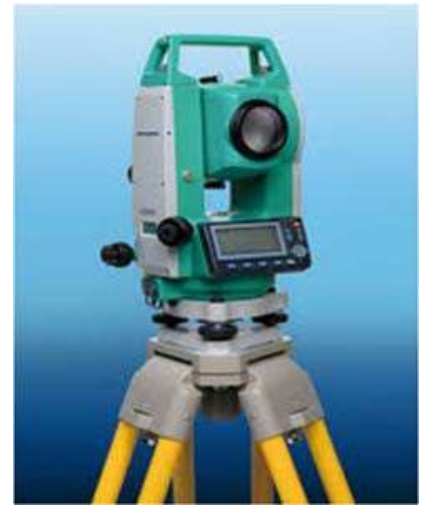

Gambar 2.3. Alat Theodolite

\section{METODOLOGI PENELITIAN}

Lokasi penelitian dilakukan pada bangunan Bank X yang terdapat pada Jl. Lambung Mangkurat, Banjarmasin, Kalimantan Selatan. Secara fungsi bangunan tersebut merupakan bangunan yang brfungsi sebagai peerkantoran. Jenis bangunan tersebut mempunyai konsruksi struktur beton bertulang dengan jumlah lantanya sebanyak 8 lantai. Lokasi penelitian bangunan bank X dapat dilihat pada Gambar 3.1.

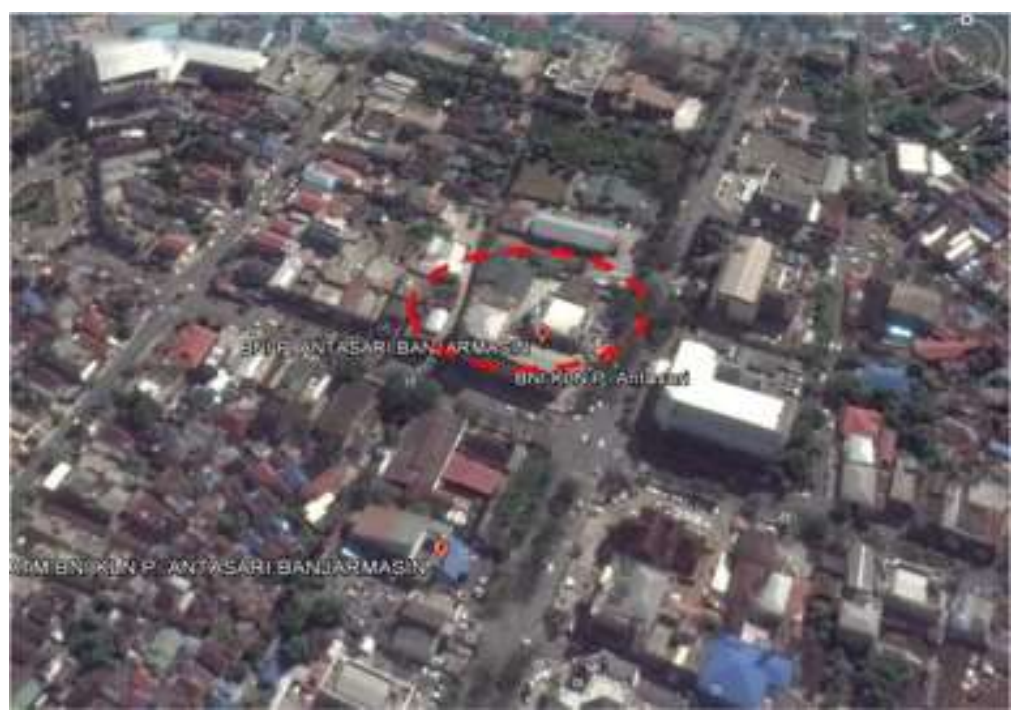

Gambar 3.1. Peta Lokasi 
Sebelum memulai pengujian struktur ada tahap persiapan dimana pada tahap ini terdapat pengumpulan data primer dan data sekunder yang akan di periksa kelengkapannya sebagai acuan pengujian. Data-data yang diperlukan dalam proses pengumpulan Gambar as built drawing, yaitu: 1) Gambar denah bangunan tiap lantai, 2) Gambar tampak muka dan tampak samping, 3) Gambar potongan horizontal dan vertical, 4) Gambar konstruksi dan struktur bangunan, dan 5) Laporan pengujian struktur terdahulu. Secara umum, metode dalam rencana kerja yang akan dilaksanakan untuk pekerjaan Pengujian Struktur Bangunan Gedung Bank X Kota Banjarmasin ini meliputi beberapa tahap kegiatan. Kegiatan yang akan dilakukan dapat dirumuskan dengan diagram alir yang terdapat pada Gambar 3.2.

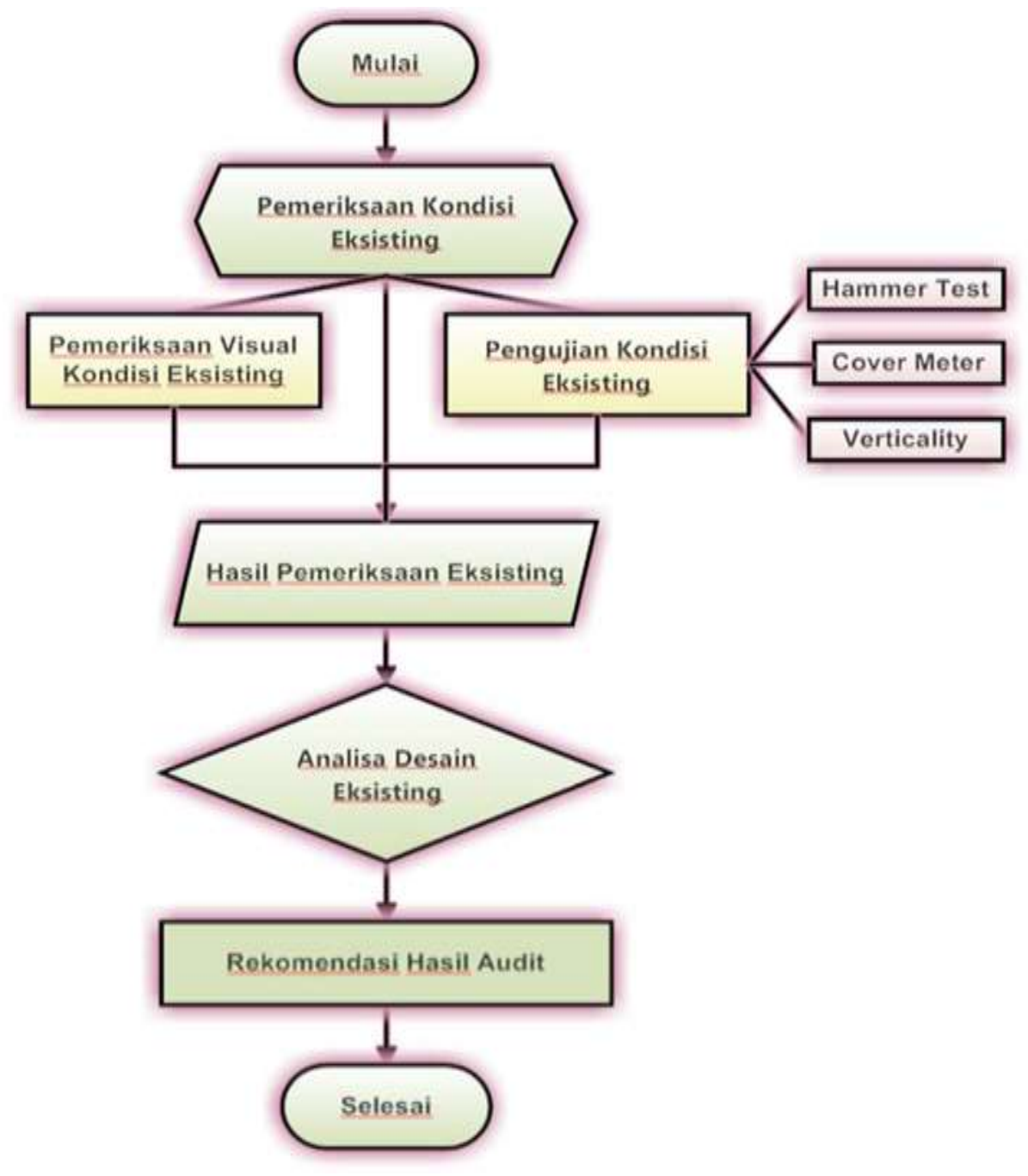

Gambar 3.2. Diagram Alir Pekerjaan pengujian struktur 


\section{ANALISIS DAN PEMBAHASAN}

Berdasarkan pemeriksaan kelengkapan data bangunan Gedung Bank X Kota Banjarmasin, gambar konstruksi dan struktur dinyatakan kurang lengkap dan informatif sehingga harus dilakukan survey geometris dan mengukur ulang serta membuat ulang gambar struktur berdasarkan kondisi eksisting sebagai acuan pengujian. Secara Pemeriksaan kondisi eksisting terbagi menjadi 2 bagian, yaitu pemeriksaan visual dan pemeriksaan pengujian struktur yang bersifat tidak merusak. Pemeriksaan secara visual dapat dilihat pada Gambar 4.1.
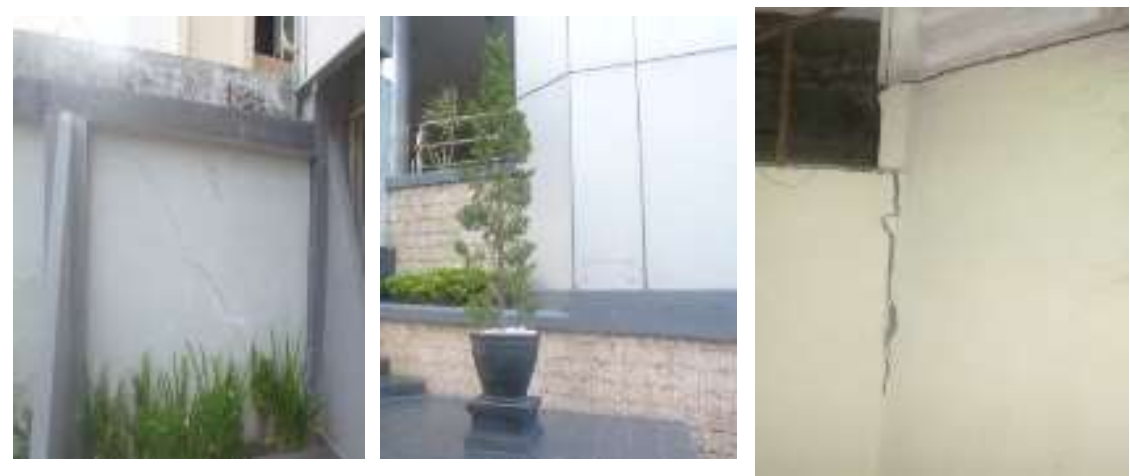

Gambar 4.1. Kerusakan struktural dan non struktural

Pengujian Struktur Bersifat Tidak Merusak (Undestructive) terdiri dari 2, yaitu: 1) Pengujian kuat tekan beton (Hammer Test) dan Pengujian Rebar Locator/Cover meter. Pengujian kuat tekan beton dengan menggunakan alat Hammer Test dilakukan dengan menguji 38 titik yang terdiri dari 25 titik kolom, 9 titik Balok dan 4 titik pelat. Dokumentasi pengujian Hammer test dapat dilihat pada Gambar 4.2.
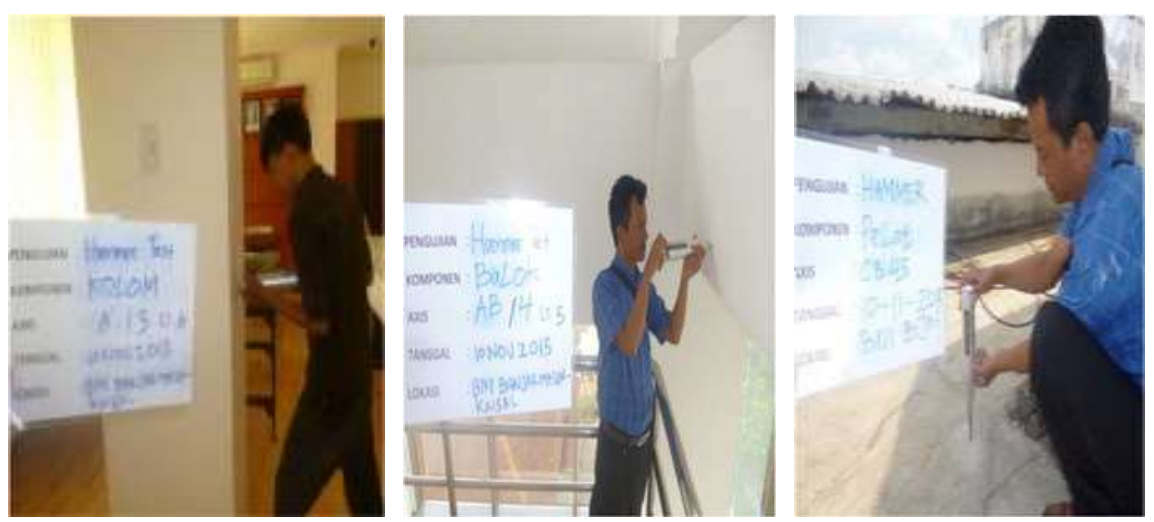

Gambar 4.2. Dokumentasi Pengujian Hammer Test 
Setelah dilakukan pengujian kuat tekan beton maka didapatkan data dan hasil yang terdapat pada Tabel 4.1.

Tabel 4.1. Data Pengujian Hammer Test

\begin{tabular}{|c|c|c|c|c|c|c|c|}
\hline \multirow{2}{*}{\multicolumn{2}{|c|}{$\begin{array}{l}\text { ELEMEN STRUKTUR } \\
\text { SUDUT PUKULAN }\end{array}$}} & \multicolumn{2}{|c|}{ PELAT } & \multicolumn{2}{|c|}{ BALOK } & \multicolumn{2}{|c|}{ KOLOM } \\
\hline & & 90 & -90 & 0 & 90 & 0 & 0 \\
\hline \multicolumn{2}{|c|}{ KODE BIDANG UJ } & & & $\mathrm{BDC5}$ & BD34 & KB2 & KB2 \\
\hline \multirow{10}{*}{$\begin{array}{l}\text { NILAI } \\
\text { LENTING } \\
\text { PALU } \\
\text { BETON } \\
(\mathrm{R})\end{array}$} & 1 & 22 & & 39 & 42 & 42 & 40 \\
\hline & 2 & 21 & & 40 & 38 & 43 & 44 \\
\hline & 3 & 20 & & 43 & 39 & 38 & 33 \\
\hline & 4 & 20 & & 39 & 46 & 43 & 32 \\
\hline & 5 & 19 & & 41 & 42 & 38 & 38 \\
\hline & 6 & 23 & & 43 & 44 & 35 & 40 \\
\hline & 7 & 22 & & 40 & 44 & 43 & 39 \\
\hline & 8 & 20 & & 40 & 40 & 43 & 33 \\
\hline & 9 & 24 & & 42 & 43 & 38 & 37 \\
\hline & 10 & 24 & & 41 & 40 & 41 & 41 \\
\hline \multicolumn{2}{|l|}{ R MAKSIMUM } & 24 & & 43 & 46 & 43 & 44 \\
\hline \multicolumn{2}{|l|}{ R MINIMUM } & 19 & & 39 & 38 & 35 & 32 \\
\hline \multicolumn{2}{|l|}{ R RATA - RATA } & 21.5 & & 40.8 & 41.8 & 40.4 & 37.7 \\
\hline \multicolumn{2}{|c|}{$\begin{array}{l}\text { PERKIRAAN KUAT } \\
\text { TEKAN BETON } \\
\text { TERKOREKSI }\left(\mathrm{N} / \mathrm{mm}^{2}\right)\end{array}$} & 15 & & 36 & 40 & 36 & 31 \\
\hline
\end{tabular}

Hasil kuat tekan beton per elemen struktur tersebut dihasilkan dari nilai ratarata lenting palu beton yang dikonversi dengan grafik hubungan nilai lenting palu beton. Setelah semua elemen struktur diuji, maka hasil dari keseluruhan kuat tekan beton dapat dilihat pada Tabel 4.2.

Tabel 4.2. Hasil Pengujian Hammer Test

\begin{tabular}{|l|c|c|c|c|}
\hline \multicolumn{1}{|c|}{ Uraian } & Pelat & Balok & Kolom & Kuat Tekan Beton Dipakai (N/mm2) \\
\hline $\begin{array}{l}\text { Jumlah rata-rata } \\
\text { Kuat Tekan Beton } \\
\text { (N/mm2) }\end{array}$ & 22.80 & 25.04 & 23.46 & 23.77 \\
\hline
\end{tabular}

Pengujian Rebar Locator/Cover meter merupakan Pengujian dengan menggunakan alat Profometer Testing Apparatus. Pengujian ini merupakan pengujian dengan teknologi yang menggunakan The pulse-induction method. Metoda ini menggunakan induksi gelombang elektromagnetik untuk mendeteksi baja tulangan. Coil pada probe secara periodik dapat dibebani arus gelombang sehingga menghasilkan medan magnet. Permukaan bahan yang konduktif akan menginduksi medan magnet dalam arah yang berlawanan. Perubahan yang dihasilkan dalam tegangan ini yang digunakan untuk pengukuran. Baja tulangan yang lebih dekat dengan probe atau ukuran yang lebih besar akan menghasilkan medan magnet yang kuat. Pemrosesan sinyal selain membantu melokalisasi pembacaan baja tulangan, juga dapat menentukan tebal cover beton dan mengestimasi diameter tulangan. Metode pengujian ini tidak dipengaruhi oleh bahan non konduktif seperti beton, kayu, plastik, batu bata. Namun setiap jenis bahan konduktif dalam medan magnet akan memiliki pengaruh pada hasil pengukuran. 
Pengujian yang dilakukan dengan menggunakan sampel19 titik uji, diantaranya 3 titik uji pelat, 5 titik uji balok dan 11 titik uji kolom. Hasil pengujian rebar locator dapat dilihat pada Tabel4.3.

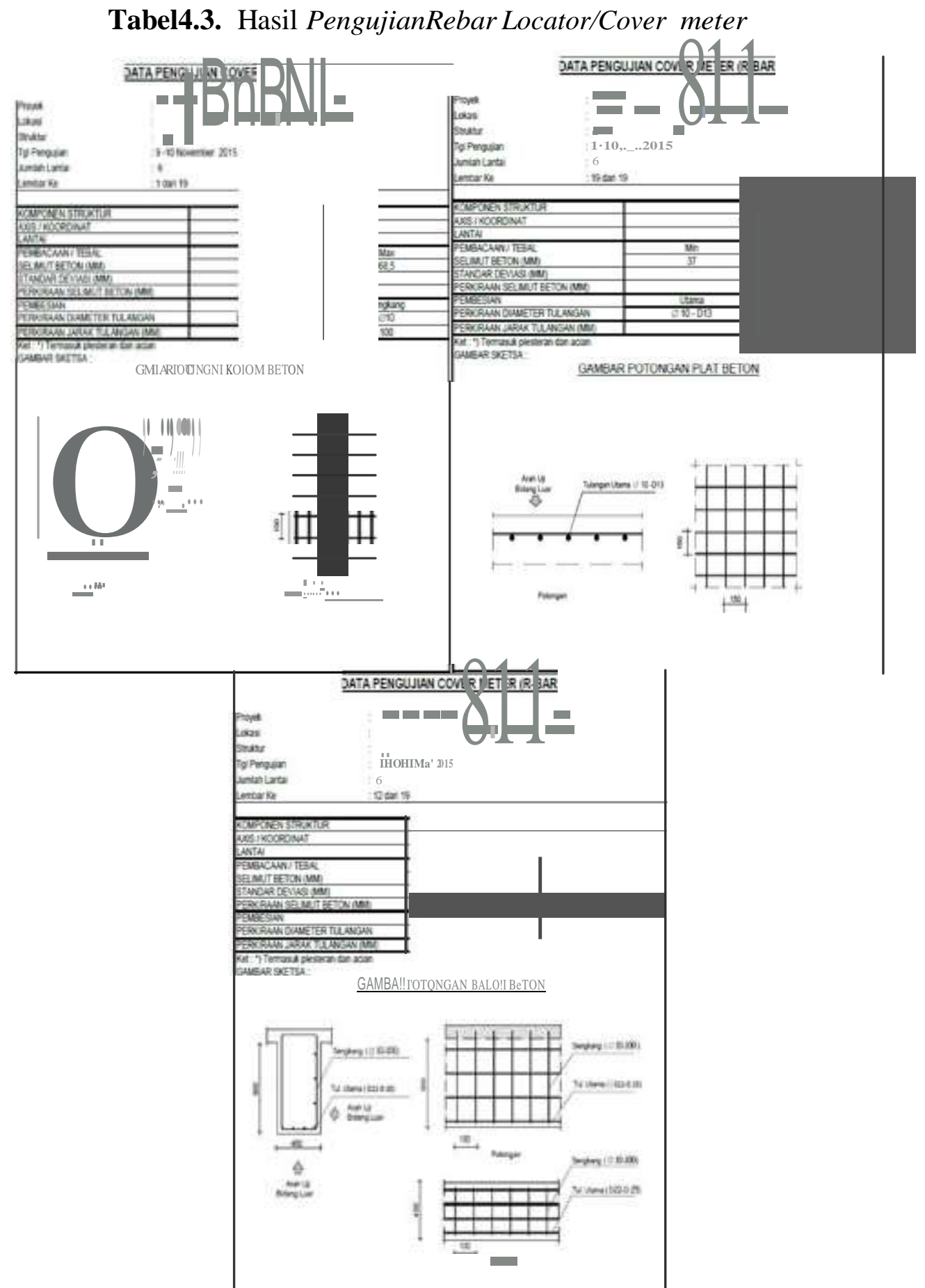



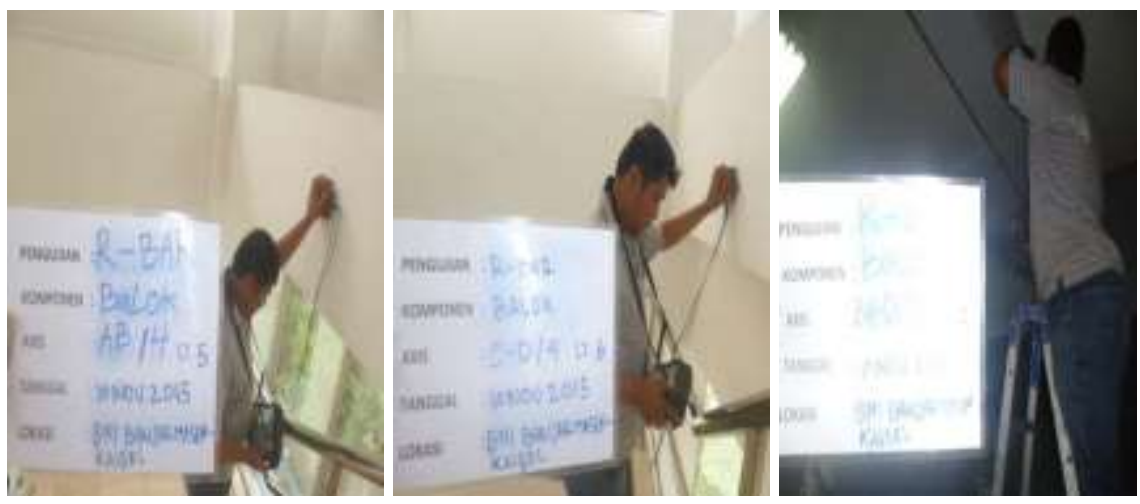

Gambar 4.3. Dokumentasi Pengujian Rebar Locator/Cover meter

Pemeriksaan Verticality/Kemiringan Bangunan merupakan pengujian atau Pengukuran kemiringan bangunan yang bertujuan untuk menentukan apakah nilai kemiringan suatu bangunan masih memenuhi toleransi kemiringan yang diijinkan oleh standar peraturan yang berlaku ataupun tidak. Hasil pengukuran dapat memberikan masukan kemudian yang akan dilakukan dalam menentukan tindakan tepat selanjutnya agar bangunan tetap dapat memenuhi kebutuhan sesuai dengan fungsinya. Pemeriksaan kemiringan Gedung Bank X Kota Banjarmasin dilakukan dengan pengambilan sampel pengujian sebanyak 2 titik uji, yaitu: 1) bagian depan bangunan. Hasil survey pengujian verticality/ kemiringan dapat dilihat, yaitu: 1) Batas kemiringan yang diijinkan untuk Batas Kemiringan merupakan $0.025 \mathrm{X}$ Tinggi Bangunan dengan 0,025x18 menjadi $45 \mathrm{~cm} ., 2$ ) bagian Muka Kanan A, Kemiringan = $19 \mathrm{~mm}<$ dari $450 \mathrm{~mm}$ (batas kemiringan yang diijinkan), Jadi kemiringan pada bagian Muka Kanan A masih di ijinkan, 3) Untuk bagian Muka Kiri $\mathrm{B}$, Kemiringan $=66 \mathrm{~mm}<$ dari $450 \mathrm{~mm}$ (batas kemiringan yang diijinkan), Jadi kemiringan pada bagian Muka Kiri B masih di ijinkan.

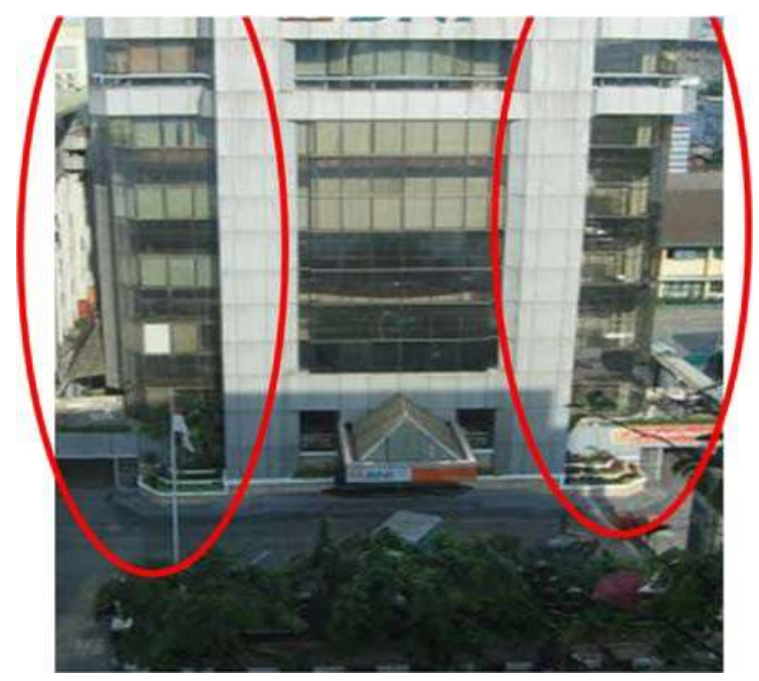

Gambar 4.4. Lokasi Titik Pengujian Verticality/Kemiringan Bangunan 

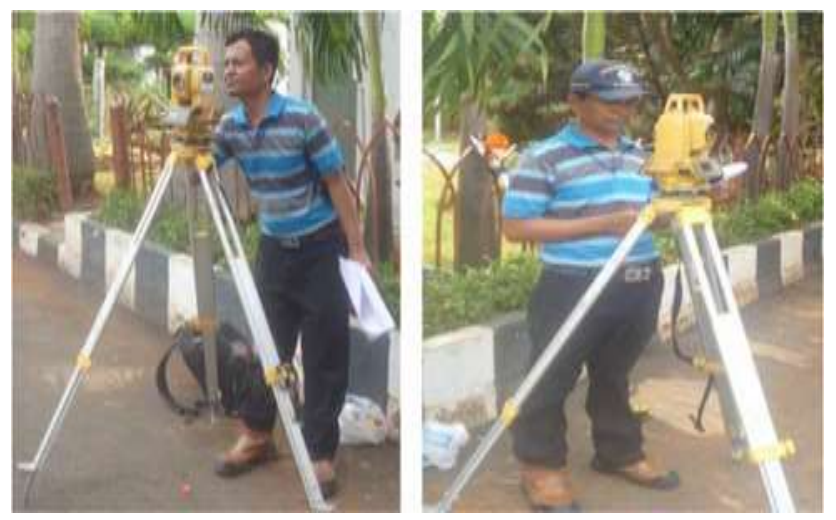

Gambar 4.5. Dokumentasi Pengujian Verticality/Kemiringan Bangunan

Dari keseluruhan hasil pengujian eksisting bangunan gedung Bank X Kota Banjarmasin, maka langkah selanjutnya adalah menganalisa struktur dengan cara memodelkannya menggunakan Software analisa struktur. Hasil yang didapatkan dari pemeriksaan secara analisis struktur dengan Kriteria Pembebanan, yaitu:

a. Beban Mati (DL)

Material Struktur Baja dengan kerapatan massa 7850 kg/m3, dan Beton

Bertulang dengan kerapatan massa $2400 \mathrm{Kg} / \mathrm{m} 3$

b. Beban Mati Tambahan (SDL)

Asumsi beban mati tambahan (superimposed dead load) yang ditanggung oleh komponen struktur terdiri atas:

- Penutup Rangka Atap (Spandek) : $5 \mathrm{~kg} / \mathrm{m} 2$.

- Mechanical Electrical, and Plumbing (MEP) : $12 \mathrm{~kg} / \mathrm{m} 2$.

- Dinding bata Ringan : $100 \mathrm{~kg} / \mathrm{m} 2$

- Dinding lantai (screed) dan Finishing $\quad: 120 \mathrm{~kg} / \mathrm{m} 2$

c. Beban Hidup (LL)

Asumsi Beban hidup yang diterapkan dalam desain ini terdiri atas :

- Untuk Bangunan Gedung : $\quad: 400 \mathrm{~kg} / \mathrm{m} 2$

- Untuk Bangunan Tangga $\quad: 300 \mathrm{~kg} / \mathrm{m} 2$

- Untuk Bangunan Selasar : $250 \mathrm{~kg} / \mathrm{m} 2$

d. Beban Gempa

Beban Gempa ditentukan sesuai dengan yang disyaratkan oleh Tata Cara Perencanaan Ketahanan Gempa Untuk Bangunan Gedung, SNI 1726-2012. Beban gempa direncanakan berdasarkan SNI 1726-2012; dengan terletak pada Ss Ss 0.06g ; S1 $0.036 \mathrm{~g}$, adapun sesuai factor peruntukannya yaitu Toko/pasar, maka termasuk kepada katagori resiko III dan faktor keutamaanya Ie $=1.25$. 


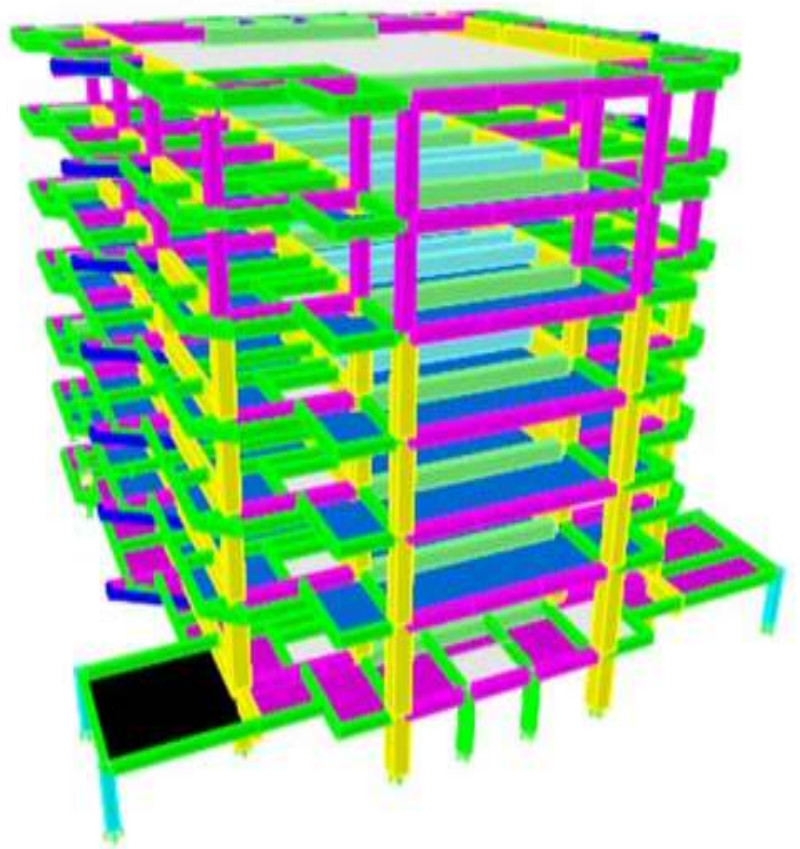

Gambar 4.6. Modeling 3D Extrude

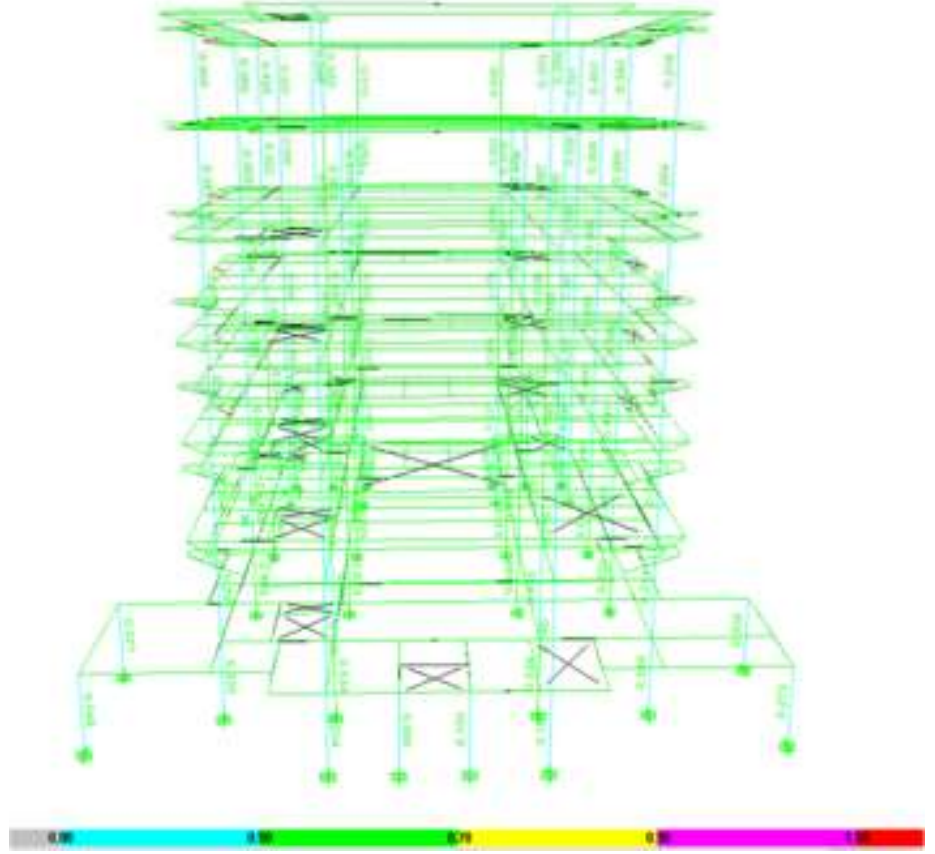

Gambar 4.7. Stress Steel Ratio 


\section{KESIMPULAN}

Berdasarkan hasil pengujian dan investigasi yang telah dilakukan, maka dapat diambil kesimpulan, yaitu: 1) hasil pengamatan visual struktur gedung Bank X Kota Banjarmasin yang telah dilakukan pada tanggal 09 November 2015, struktur gedung masih cukup kuat. Akan tetapi terdapat kerusakan non struktur dan kerusakan struktur Tingkat Sedang yang harus segera diperbaiki. Tindakan yang perlu dilakukan ialah perbaikan-perbaikan (repair) secara arsitektur khusunya perbaikan arsitektur yang dekat daerah struktur seperti kolom dan balok, 2) Pada hasil pengujian Hammer test bangunan gedung Bank X Kota Banjarmasin. telah terlaksana 38 titik uji, diantaranya 4 titik uji pelat, 9 titik uji balok, dan 25 titik uji kolom. Dengan hasil kuat tekan beton sebesar 22.825 MPa atau Mutu Beton K-275, 3) Hasil Pengujian Cover Meter untuk mengetahui kedalaman posisi baja tulangan dan jumlah baja tulangan serta diameter baja tulangan yang ada di dalam penampang beton, 4) Pada hasil pengujian Verticality Test bangunan gedung Bank X Kota Banjarmasin, Untuk bagian Muka Kanan A kemiringan pada bagian Muka Kanan A masih di ijinkan, Untuk bagian Muka Kiri B, kemiringan pada bagian Muka Kiri B masih di ijinkan. Analisis struktur gedung secara keseluruhan dihasilkan Stress rasio nilai kolom yang terjadi adalah $<1$ atau struktur kolom tidak berwarna merah; maka desain struktur cukup kuat untuk menahan beban yang terjadi.

\section{DAFTAR PUSTAKA}

Badan Strandarisasi Nasional (BSN). (1997). Tentang Metode Pengujian Tekan Elemen Struktur Beton Dengan Alat Palu Beton Tipe N dan NR, SNI 03-44301997. Jakarta, Badan Strandarisasi Nasional (BSN).

Badan Strandarisasi Nasional (BSN). (2013). Beban Minimum Untuk Perencanaan Bangunan Gedung Dan Struktur Lain SNI 1727:2013. Jakarta, Badan Strandarisasi Nasional (BSN).

Badan Strandarisasi Nasional (BSN). (2015). Spesifikasi Untuk Bangunan Gedung Baja Struktural, SNI 1724.9:2015. Jakarta, Badan Strandarisasi Nasional (BSN). Badan Strandarisasi Nasional (BSN). (2013). Persyaratan Beton Struktural Untuk Bangunan Gedung, SNI 2847:2013. Jakarta, Badan Strandarisasi Nasional (BSN).

Badan Strandarisasi Nasional (BSN). (2013). Tata Cara Perencanaan Ketahanan Gempa Untuk Struktur Bangunan Gedung Dan Non Gedung SNI 1726:2012. Jakarta, Badan Strandarisasi Nasional (BSN).

British Standar. (1881). Recommendations on the Use of Electromagnetic Covermeters. 